Revista Estudios, (40), 2020.

Junio 2020-Noviembre 2020

ISSN 1659-3316

Barboza Leitón Ivannia

Calvo Oviedo Marlen María

Dossier: La escritura en los desplazamientos: viajes, expediciones y naufragios

\title{
Mateo Rosas de Oquendo. Un viaje y un romance: el yo lírico ante el nuevo mundo
}

\author{
Ivannia Barboza Leitón, \\ Universidad de Costa Rica, Costa Rica \\ ivannia.barboza@ucr.ac.cr \\ https://orcid.org/0000-0003-0057-1981
}

\author{
Marlen María Calvo Oviedo, \\ Universidad de Costa Rica, Costa Rica \\ marlen.calvo@ucr.ac.cr \\ https://orcid.org/0000-0002-0824-4398
}

Recibido: 14 de febrero de 2020

Aceptado: 30 de marzo de 2020

Resumen: Este artículo analiza un fragmento de un romance atribuido a Mateo Rosas de Oquendo que data del siglo XVI. El análisis se enfoca en el relato de viajes concebido como una acción elemental, que atraviesa la gran mayoría de los textos producidos o escritos desde el siglo XV al XVII, cuyo referente es el desplazamiento entre España y la América española. La semántica textual deslinda el fragmento de las valoraciones de verosimilitud a las que podría ser sometido, para ello se emplea la semiosis de lo relatado, sin establecer la relación entre lo que pueda ser factual y lo que pueda ser ficción. En el peregrinar del yo lírico se aglutinan acciones como dimensionar los espacios y enfrentarse a retos personales ante lo desconocido. En un mundo descrito como un continente de exageraciones, Rosas de Oquendo, emprende un viaje de desplazamiento geográfico que lo lleva a descubrir y a descubrir(se).

\section{(C) $(0 \otimes)$}

La Revista Estudios es editada por la Universidad de Costa Rica y se distribuye bajo una Licencia Creative Commons Atribución-NoComercial-CompartirIgual 3.0 Costa Rica. Para más información envíe un mensaje a 
Dossier: La escritura en los desplazamientos: viajes, expediciones y naufragios

Palabras clave: Literatura colonial latinoamericana; romance satírico; Rosas de Oquendo; Nombre de Dios; Nuevo Mundo.

\title{
Mateo Rosas de Oquendo. A journey and a romance: the lyrical self before the new world
}

\begin{abstract}
This article analyzes a fragment of a romance attributed to Mateo Rosas de Oquendo dating from the 16th century. The analysis focuses on the travel story conceived as an elementary action, which crosses the vast majority of the texts produced or written from the fifteenth to the seventeenth century, whose reference is the displacement between Spain and Spanish America. Textual semantics delimits the fragment of the similar assessments to which it could be submitted, for this the semiosis of the narrative is used, without establishing the relationship between what can be factual and what can be fiction. In the pilgrimage of the lyrical self, actions such as dimensioning spaces and facing personal challenges to the unknown are brought together. In a world described as a continent of exaggerations, Rosas de Oquendo, embarks in a journey of geographical displacement to discover both himself and new lands.
\end{abstract}

Keywords: Latin American colonial literature; satirical romance; Rosas de Oquendo; Nombre de Dios; New World.

\section{INTRODUCCIÓN}

Emprender un viaje y dar cuenta de este, es una tarea que representa una movilización no solo física, sino también mental. Cuando Cristóbal Colón escribe la primera carta de la que se tenga conocimiento como conquistador de Las Indias, anota para la historia el registro de los acontecimientos y da razón a una burocracia monárquica de lo que tal acto significa, lo que representa una reelaboración para sí mismo, de lo visto, lo conocido y lo recién adquirido en sus viajes. Esa primera impresión escrita data de 1493 en la que se refieren pocos datos del desplazamiento emprendido por el navegante genovés, pero sí se describen las tierras a las cuales llegaron (Cuba y La Española) con las naves que habían desembarcado del Viejo Continente.

\section{(c) (i) (-)}

La Revista Estudios es editada por la Universidad de Costa Rica y se distribuye bajo una Licencia Creative Commons Atribución-NoComercial-CompartirIgual 3.0 Costa Rica. Para más información envíe un mensaje a 
ISSN 1659-3316

Barboza Leitón Ivannia

Dossier: La escritura en los desplazamientos: viajes, expediciones y naufragios

Como es sabido a este primer protocolo escrito de un viaje, le sucedieron infinidad de cartas, crónicas, bitácoras y otros documentos, en los que los viajeros (quienes se trasladaron de un espacio geográfico situado allende los océanos) para buscar la aventura de sus vidas, hicieron de la palabra escrita el código desde el cual demostrar la magnificencia de las nuevas tierras. El acto de escritura los insertó en la historia como personajes, escribas y conquistadores de América.

El objetivo que acompaña este artículo es analizar un fragmento del texto poético (un romance que data del siglo XVI) escrito por Mateo Rosas de Oquendo, cuyo título es Respuesta que un amigo escribió a otro (Felisio, tu carta vide). El poema completo se ubicó en un Cartapacio junto con otras composiciones poéticas que dan cuenta de las lecturas, las travesías y los avatares sazonados con picardía, ironía y sarcasmo del que fuera un viajero español de la Colonia en América. Elegimos, para este análisis, un segmento sencillo de 80 líneas que da cuenta del embarco en España y el recorrido por altamar hasta llegar a Nombre de Dios (Panamá).

Nuestro presupuesto teórico, en este artículo, en lo referente a la escritura de viajes parte de lo que señala Luis Alburqueque García (2011b). Él acota que la tradición humana de dar cuenta por escrito u oralmente de los relatos de viajes es ancestral, mítica y mágica, también lo es como testimonio de lo que se experimenta. Alburqueque García (2011a) cita como ejemplos de maravillosos viajes los relatados de la Odisea, los textos de Alejandro de Macedonia, el desplazamiento del ilustre hidalgo don Quijote, entre otros.

Por lo anterior, nos parece preciso centrar el enfoque de análisis en el relato de viajes concebido como una acción elemental, que atraviesa la gran mayoría de los textos producidos o escritos desde el siglo XV al XVII, cuyo referente es el desplazamiento entre España y la América española, sea este desde tierra o marítimo (embarcaciones). Consideramos que dichos relatos comprenden un

\section{(@) $\odot \odot$}

La Revista Estudios es editada por la Universidad de Costa Rica y se distribuye bajo una Licencia Creative Commons Atribución-NoComercial-CompartirIgual 3.0 Costa Rica. Para más información envíe un mensaje a 
ISSN 1659-3316

Barboza Leitón Ivannia

Dossier: La escritura en los desplazamientos: viajes, expediciones y naufragios proceso y una consecuencia, es un discurso sobre los acontecimientos vividos de quien narra, se constituye con ello un hilo de sucesos y apuros.

El relato de viajes muestra múltiples facetas por lo que su caracterización, por demás heterogénea, es el resultado de lo que el teórico español comenta en la siguiente cita "Nos hallamos, pues, ante un género en el que confluyen la dimensión histórica (más permeable al «yo» y más predispuesto a «lo literario»), y la ficticia (más inclinada hacia lo testimonial)" (Alburqueque García, 2011a, p. 31). Agrega, además tres rasgos fundamentales del relato de viajes. Son relatos factuales, en los que, la modalidad descriptiva se impone a la narrativa y en la relación subjetivoobjetivo, por su carácter testimonial, pondera lo subjetivo. Alburqueque García refiere a Genette, cuando menciona que "el relato factual nace, se desarrolla y termina siguiendo el hilo de unos hechos realmente acaecidos que forman su columna vertebral (2011b, p. 17).

El carácter literario, al decir de Alburqueque García, está manifiesto en “(...) la factualidad de estos relatos, cuyo componente cronológico y topográfico remite a un tiempo y un espacio vividos por el viajero, no excluye su condición de literarios" (2011b, p. 17); es decir, desde nuestra visión respecto de este punto, el acto de narrar no se deslinda del de describir, ya que existe en esos textos una amalgamada relación entre el discurso que testimonió experiencias y el que desarrolló habilidades para estructurar y narrar.

Conjuntamos también la semántica textual, para lograr deslindar el fragmento en estudio de las valoraciones de verosimilitud a las que podría ser sometido, por lo que partimos de la premisa de que es escritura y como tal otorga sentidos; establecemos un acercamiento desde la semiosis de lo relatado en el romance, sin abocarnos a instituir la relación entre lo que pueda ser factual y lo que pueda ser ficción (en caso de haberla).

\footnotetext{
(c) (1) (2)

La Revista Estudios es editada por la Universidad de Costa Rica y se distribuye bajo una Licencia Creative Commons Atribución-NoComercial-CompartirIgual 3.0 Costa Rica. Para más información envíe un mensaje a revistaestudios.eeg@ucr.ac.cr.
} 
Dossier: La escritura en los desplazamientos: viajes, expediciones y naufragios

\section{SOBRE MATEO ROSAS DE OQUENDO}

Mateo Rosas de Oquendo, español, "(...) que otro tiempo fue Juan Sánches (...)" (Lasarte, 1990, p. 375), habría nacido en Andalucía, probablemente en Sevilla (Carilla, 1996, p. 442), por ahí de 1559, año que críticos e investigadores señalan como su probable fecha de nacimiento a partir del suceso que el mismo Rosas de Oquendo anotó en sus textos poéticos: "Porque él dice que en 1598 tenía treinta y nueve navidades (...)" (Paz y Meliá, 1906, p.155). Emprendió viaje hacia América aproximadamente en 1583 (Lasarte, 1988, p. 91), ahí emplea su nombre de Juan Sánches, recorre México, Perú y regresa a morir a España.

En Perú se asienta en Tucumán bajo la protección del gobernador Ramírez de Velazco, en 1593 o 1594 se va a Lima, donde gozó de la protección del Virrey García Hurtado de Mendoza (al menos por un tiempo), llega a México en 1598. Se sabe que vivía aun en 1612, que posiblemente murió en Sevilla, se desconoce la fecha exacta, esto lo señala Alfonso Reyes, pero no lo fundamenta.

En cuanto a la personalidad de Rosas de Oquendo destacan las afirmaciones acerca de su carácter dinámico, satírico y audaz, su fuerte inclinación hacia las mujeres, lo que se le facilitaba por su aspecto físico de complexión delgada, su cabello rojo y ojos negros, además por su disposición al verso. Paz Meliá dice que Rosas de Oquendo parece haber sido "más atento a los goces de la materia que a los del espíritu" (Paz Meliá citado por Reyes, 1957, p. 26).

La producción de Rosas de Oquendo no fue vasta, es su personalidad veleidosa y su carácter satírico lo que permitirá conocer una perspectiva diferente del viaje, y la conquista fuera de la queja constante de los conquistadores y otros escritores de América del siglo XVI. Respecto de este punto Emilio Carilla (1996) dice:

\section{(๑) $\odot \odot$}

La Revista Estudios es editada por la Universidad de Costa Rica y se distribuye bajo una Licencia Creative Commons Atribución-NoComercial-CompartirIgual 3.0 Costa Rica. Para más información envíe un mensaje a 
Dossier: La escritura en los desplazamientos: viajes, expediciones y naufragios

A través de su no muy amplia producción, Rosas de Oquendo nos da algo así como la versión satírica y burlona de la conquista, frente a los consabidos testimonios de los conquistadores (...) Por otra parte, Rosas de Oquendo nos ha dejado otras noticias, vestidas más o menos líricamente, en que apunta hacia las debilidades y rasgos minúsculos de aquella sociedad, niña en años pero crecida en enconos y apetitos (...) (p. 443).

A principios de 1900, Antonio Paz y Meliá, biógrafo e historiador español, publica un Cartapacio del siglo XVI que se conserva en la Biblioteca Nacional de Madrid, el tejuelo del cartapacio reza: Sátira de Oquendo, allí se encontraron poemas de distintos autores (Cervantes, Góngora y Quevedo, entre otros) y del mismo Rosas de Oquendo, esto lo catapulta no solo como poeta, sino también como biógrafo de la época. Con estas afirmaciones sí puede colegirse que el vate no solo fue aventurero, sino también lector incansable y conocedor de las letras españolas de la época.

No obstante, la incertidumbre propia del momento en cuanto a determinar la autoría o no de todos los textos poéticos del Cartapacio, permea su producción, al respecto anotamos: "De las doscientas cuarenta y ocho composiciones que integran el «Cartapacio poético», por lo menos ciento diez tienen un carácter burlesco, en un diapasón que abarca de lo joco-serio a lo obsceno, pasando por lo erótico-burlesco y lo escatológico" (Peña, 1986, p. 668). En dichos textos literarios sobresalen poemas amorosos, moriscos, de motivación religiosa, sobre personajes famosos como reyes y otros nobles.

Rodilla León señala que Rosas de Oquendo es un poeta satírico (1998, p.78) y coincide con Oviedo Pérez de Tudela (2008, p. 349). La capacidad de Rosas de Oquendo desborda en la palabra fácil y la idea ingeniosa en donde, el Nuevo Mundo al que se enfrenta le proveen de posibilidades (materiales y humanas) para colocar en el papel sus versos. Rosas de Oquendo cultivó el género poético y el narrativo, además de ser compilador de otras composiciones que agrupó en el Cartapacio. El

\section{(c) (i) (2) (2)}

La Revista Estudios es editada por la Universidad de Costa Rica y se distribuye bajo una Licencia Creative Commons Atribución-NoComercial-CompartirIgual 3.0 Costa Rica. Para más información envíe un mensaje a 
ISSN 1659-3316

Barboza Leitón Ivannia

Dossier: La escritura en los desplazamientos: viajes, expediciones y naufragios caso que nos ocupa da cuenta de un romance, estilo común y sencillo que le proporciona la posibilidad expedita para dar cuenta de su aventura en América. Recordemos que el romance, de origen español, emplea la métrica de ocho sílabas, en cuyos versos pares se reconoce asonancia y en los impares ausencia de rima.

Cabe extrapolar las cualidades de los relatos de viaje a los escritos de Mateo Rosas de Oquendo, quien fue un individuo con existencia real que vive un viaje (factual), él escribe un texto literario para narrar su experiencia. Reconocemos la tradición en la que surge el romance como manifestación proveniente de la poesía cancioneril de las cortes, Menéndez Pidal (1953) aseveraba que

(...) los romances tradicionales se revisten de las galas de la poesía cancioneril, procedimiento a partir del cual ganan su espacio literario en forma de cancioneros de romances y de pliegos sueltos que difunde la incipiente industria editorial en toda la península" (p. 27).

Si el romance se nutre de lo sucedido para cantar y fijarlo en el eje espaciotiempo, no es de extrañar que Mateo Rosas de Oquendo lo escogiera como el estilo literario desde el cual relataría su experiencia del viaje y su visión sobre el mundo que veía por vez primera frente a sus ojos.

El viajero/poeta se sirve de las formas clásicas del romance que le proveen el estilo literario y de su experiencia para formar una especie de fusión entre el relato de viaje y la poesía. El interés de Rosas de Oquendo parece ir más allá de la pura descripción testimonial de lo que le acaece y de lo que ve, también pretende hacer alarde de la sátira, la ironía (lenguaje poético muy característico del romance) y del manejo de la forma estructural del estilo, es decir, se posiciona a sí mismo como poeta (literato).

Daniel Eisenberg (1991), estudioso de Cervantes agrega que el romance fue considerado por este último un género narrativo, y como la más prosaica de las formas poéticas, más que literatura era historia (párr. 6). Eisenberg acota que los

\section{(c) (i) (-)}

La Revista Estudios es editada por la Universidad de Costa Rica y se distribuye bajo una Licencia Creative Commons Atribución-NoComercial-CompartirIgual 3.0 Costa Rica. Para más información envíe un mensaje a 
ISSN 1659-3316

Barboza Leitón Ivannia

Calvo Oviedo Marlen María

Dossier: La escritura en los desplazamientos: viajes, expediciones y naufragios diccionarios bilingües (español, italiano y francés) de la época lo definen como una canción pero con un contenido histórico. De ahí el interés y la relación que estableceremos entre el romance, el viaje y la llegada del yo lírico a América.

Para Menéndez Pidal, un vasto romancero debe haber llegado a América en los barcos a partir de la memoria de quienes tripulaban las naves, los descubridores, los misioneros, los soldados, los funcionarios, los poetas y literatos de oficio, pues era parte del bagaje cultural tradicional de la época ya que los versos de los romances acostumbraban expresar los valores de la comunidad, además de contener historias y ejemplos de vida.

Debemos apuntar que para el análisis semántico del texto escrito por Mateo Rosas de Oquendo, acudimos también a la noción teórica del intertexto. El mundo no podría ser relatado, poetizado, narrado o descrito sin que pudiera acudirse al intertexto, como todo aquel indicio que nos permita rastrear la procedencia y el conocimiento del mundo pre-viaje de la voz lírica que se expresa en el romance. Alburquerque García acota que la intertextualidad se presenta en la utilización como referente de "(...) los relatos bíblicos, los romances, y las novelas de caballerías 0 algunos textos jurídicos (...) son lecturas que están consciente o inconscientemente presentes" (Alburqueque García, 2011b, p. 25), aunque él se refiere a las crónicas, el concepto es útil en el caso del género literario que nos ocupa. Asimismo, Rosas de Oquendo proviene del mundo de las letras por lo que sus intertextos estarán más inclinados hacia esa línea, un ejemplo es la enunciación en la que refiere al pastor de Betis, cuya conexión está dada por la égloga pastoril.

\section{DEL PORQUÉ EL YO LÍRICO SALE DE ESPAÑA}

Nos interesa, en el caso del romance de Rosas de Oquendo, hacer filigrana con el texto, ir armando un finísimo tejido con los signos que describen el viaje, las peripecias y ese mundo detallado desde el asombro del descubrimiento: qué se dice

La Revista Estudios es editada por la Universidad de Costa Rica y se distribuye bajo una Licencia Creative Commons Atribución-NoComercial-CompartirIgual 3.0 Costa Rica. Para más información envíe un mensaje a revistaestudios.eeg@ucr.ac.cr. 
ISSN 1659-3316

Barboza Leitón Ivannia

Calvo Oviedo Marlen María

Dossier: La escritura en los desplazamientos: viajes, expediciones y naufragios y cómo lo dice. Para lo anterior, emplearemos los presupuestos metodológicos que provee la interpretación de los signos en el texto, el universo descrito, desde la síntesis de la estructura del romance, la epístola como modelo de fondo y lo factual.

Entre las páginas 42 y 45 del Cartapacio se encontró el texto que revisamos, cuyo título es Respuesta que un amigo escribió a otro (Felisio, tu carta vide), contestación que Mateo Rosas de Oquendo remite a la carta de un amigo. Es un romance extenso que relata la trayectoria desde la salida del puerto, el desplazamiento con detalles de los sitios en los que desembarca, hasta, finalmente llegar al destino: Perú. El tono epistolar no lo aleja de la sátira propia del estilo literario de Rosas de Oquendo y por el que se le conoce tanto en México como en América del Sur. El fragmento del romance, objeto de interés en este artículo, posee 80 versos, carece de elementos paratextuales más que aquel que lo motiva como respuesta amable a un amigo.

El viaje, eje de nuestro interés, es considerado por Cirlot (1997) experiencia y movimiento (pp. 459-460). Pero lo que impulsa y genera el desplazamiento mismo es motivado, en ocasiones, por un rompimiento con la normalidad de la vida, que termina por alentar a quien lo emprende el cambio, así lo enuncia en los tres primeros versos el yo lírico: "1-Digo que salí d’España/ 2- en berdor de mis años/3y el abril de mi esperança," (Reyes, 1957, pp. 27-28). Se genera el movimiento señalado por el verbo "salí" marcado a su vez, por la indicación geográfica de España como sitio de embarque. El yo lírico complementa la información cuando se describe a sí mismo como alguien joven, lleno de esperanzas, al decir de Cirlot alentado a emprender un cambio, también agregamos que según se infiere de estos tres primeros versos, el viaje se inicia en abril, época de primavera como los años mozos que dice tener el nuevo navegante.

Los versos siguientes del 4 al 11, parecen descubrir el motivo de la salida del yo lírico de España, Veamos:

\section{(c) () (-)}

La Revista Estudios es editada por la Universidad de Costa Rica y se distribuye bajo una Licencia Creative Commons Atribución-NoComercial-CompartirIgual 3.0 Costa Rica. Para más información envíe un mensaje a 
4- quando Fenis, mi enemiga,

5- tan hermosa como yngrata,

6- quiso pagar a mi fe

7- la deuda en que se hallaba.

8- En este tiempo dichoso

9- salió Belisa a la causa,

10- rrompiendo mares de fe,

11- que no hay para el ielo ama-

[rras.

El análisis semiótico, tomando en cuenta las limitaciones del tiempo y el espacio y los cambios que podrían haber sufrido los signos utilizados por la voz lírica para sustentar su discurso, diversifican el acercamiento por lo que abordaremos la semiótica desde tres ejes: práctico intuitivo, teórico y práctica profesional, José Ángel Magariños de Morentin sostiene que Pierce considera la semiosis como la lectura de los eventuales íconos, índices y símbolos que exclusiva o conjuntamente contribuyen a la construcción del texto semiótico, como su materia prima (1996, p. 18).

Continúa Magariños de Morentin anotando que el análisis semiótico deberá garantizar la verdad de sus afirmaciones acerca de cómo en determinado momento de cierta comunidad, se construyen los conceptos posibles en ese momento, cómo cambian o se mantienen los significados, lo cual acuerpa con la siguiente cita

El punto requiere disponer de una explicación plausible y adecuada (pero no universal ni definitiva) acerca de la relación entre mente, lenguaje y mundo; lo mismo acerca de la relación entre percepción e interpretación; lo mismo acerca de la relación entre estado de cosas e historia" (p.18).

Según plantea Chevalier, dentro de los simbolismos del viaje se halla la búsqueda de la paz (p. 1065). Chevalier citando a Cirlot, advierte que puede ser también la huída un motivo del desplazamiento (p. 1067). En el romance se mencionan dos mujeres (Fenis y Belisa), enemiga ingrata la una y deseosa de

La Revista Estudios es editada por la Universidad de Costa Rica y se distribuye bajo una Licencia Creative Commons Atribución-NoComercial-CompartirIgual 3.0 Costa Rica. Para más información envíe un mensaje a 
Dossier: La escritura en los desplazamientos: viajes, expediciones y naufragios poseerlo la otra, e inmediatamente los versos 12 y 13 nos confirman la huída: 12"Desterróme y desterréme;/ 13- metíme en una fregata:". Lo destierran y se destierra, es entonces que el yo lírico sufre un desplazamiento forzado por las circunstancias, posiblemente por tener que escapar de una relación con dos mujeres, lo cual como ya se ha visto, era parte de la debilidad de Rosas de Oquendo y se manifiesta en el tú lirico.

\section{VICISITUDES DEL VIAJE A NUEVAS TIERRAS}

Dentro de la "fregata" y desplegadas las velas se inicia el rumbo a lo desconocido, el viaje esperado. De ahí que antes de proseguir, consideremos datos dignos de ser advertidos. Como sabemos, el autor del poema fue parte de la milicia y eso le permitió estar en varios lugares, uno de ellos fue Génova (Italia) hacia 1585 (Carilla, p. 443), por lo que quizás utilice en el poema el término "fregata de belas". Sabemos que con la llegada de los españoles a América, España debe incorporar lenguaje referido a la navegación y los expertos en el tema eran los genoveses, es posible que el vocablo se estuviera incorporando del idioma italiano, al respecto José Ramón Carriazo (1999) refiere:

En italiano la voz tiene una historia muy peculiar: aparece por primera vez en 1350 en Boccaccio, atribuida a unos sicilianos, con la forma fregata; en 1369 se atestigua en Nápoles y pasa mucho tiempo hasta que se vuelve a documentar (p.36).

El mismo José Ramón Carriazo, siguiendo el texto de Reyes, comenta que el vocablo es usado en América por Rosas de Oquendo. Es primordial además tener presente que la fragata era un barco pequeño de auxilio en el Mar Mediterráneo a lo largo de la baja Edad Media, se adapta en el Renacimiento a la navegación atlántica (Carriazo 1999, p. 36), esto por cuanto se tiene noticias de varios

\section{(c) (i) (2)}

La Revista Estudios es editada por la Universidad de Costa Rica y se distribuye bajo una Licencia Creative Commons Atribución-NoComercial-CompartirIgual 3.0 Costa Rica. Para más información envíe un mensaje a revistaestudios.eeg@ucr.ac.cr. 
Dossier: La escritura en los desplazamientos: viajes, expediciones y naufragios problemas con ellas en los mares, a lo cual no escapa el yo lírico del texto que nos ocupa.

Una vez dentro de la embarcación se lee en los versos 14 y 15 lo siguiente: "(...) alsaron belas al viento, / xunto con la de mis ansias". Puede determinarse que se inicia la marcha cuando las velas son alzadas al viento, "la fregata" y el yo parecen fundirse en uno solo "velas al viento - ansias cumplidas", el viaje, experiencia y movimiento.

Hemos visto que las fragatas fueron adaptándose poco a poco a los viajes, pero que inicialmente no eran barcos muy grandes, sino que se modificaron para la navegación atlántica, así que no es extraño que de los versos 16 al 22, el yo lírico describa las congojas vividas en su embarque:

16- Bramó el mar, cresió los

[bientos;

17- davan mil boses: «AAmaina!

18- ¡Rrecoxe la sebadera!

19- ¡Echa el timón a la banda!»

20- Unos llamavan a Dios,

21- otros a su madre llaman:

22- "¡Arriva, que nos perdemos!

De lo anterior, el mar que brama con la fuerza de los vientos, inicia la crisis, la tripulación grita para que amaine la tormenta, él lo escucha como mil voces y lo resalta entre signos de admiración lo que le da fuerza a la solicitud, convirtiéndola casi en súplica. Emplea los dos puntos para poner en evidencia el ímpetu de dicha petición y de paso, mostrar que de boca de otro tripulante ha salido la siguiente expresión suplicante: «¡Amaina!".

En los versos 18 y 19 reconocemos que ante la eventualidad de la tormenta sufrida en mar abierto, los actos son de emergencia para contener y mantener la embarcación a flote, sin que se ponga en riesgo la vida de la tripulación, leemos: "¡Rrecoxe la sebadera!/ ¡Echa el timón a la banda!»". Recoger la vela cebadera y 
Dossier: La escritura en los desplazamientos: viajes, expediciones y naufragios echar el timón a la banda, es decir, mover la embarcación a babor o a estribor (derecha o izquierda) representa la acción poderosa de mover el barco ante el ímpetu de la tormenta con la monumentalidad que dicha nave entraña.

\section{DONDE SE PROSIGUEN LOS INAUDITOS SUCESOS DEL NAUFRAGIO}

20- Unos llamavan a Dios, 21- otros a su madre llaman:

La tormenta continúa y con ella la situación de peligro, el temor brinda voz para clamar al poder divino representado en la figura de Dios y en la imagen materna (terrenal) como apoyo para los hijos en amenaza. Asimismo, surgen dos ideas: primero, se acude a la fe, uno de los grandes motivos de la Conquista, y segundo, como hemos visto en Cirlot, el viaje es un desarraigo que se hace evidente en el llamado a la madre. Vemos la manera en que el yo lírico experimenta el viaje en un punto abismal (mar abierto) como una zona desconocida a la que se ve enfrentado con la premura de la salida de España; es entonces que para el yo lírico ". . . el espacio desconocido se ha presentado al ser humano bajo signos amenazadores" (Aínsa, 2005, p. 58).

24- Yo benía almadiado 25- como pescado en el agua, 26- tan pribado de sentido 27- como lo salí d'España.

En concordancia con la juventud del yo lírico expresada líneas arriba, se infiere que el periplo de su vida es este. Es una movilización que no solo afecta su constitución física (almadiado), sino que aflige su racionalidad, después de todo, emprender la marcha para cruzar el ponto en la búsqueda de extrañas tierras y oportunidades, involucraba la incertidumbre sobre qué haría estando en otros lares

\section{(c) (i) (2)}

La Revista Estudios es editada por la Universidad de Costa Rica y se distribuye bajo una Licencia Creative Commons Atribución-NoComercial-CompartirIgual 3.0 Costa Rica. Para más información envíe un mensaje a revistaestudios.eeg@ucr.ac.cr. 
Dossier: La escritura en los desplazamientos: viajes, expediciones y naufragios para llevar una nueva vida, de ahí no es casual que se hiciera llamar en América Juan Sánchez. Los versos del 24-27 manifiestan la experiencia novel de Mateo Rosas de Oquendo como navegante y de paso, consolidan el tono satírico (generado por circunstancias amorosas) en el que él decide acometer el traslado del Viejo al Nuevo Mundo.

En este sentido, el texto poético suple además dos aspectos reconocibles en el fondo: primero, el macro contexto de la colonización de América es el referente histórico que subyace en los versos de Mateo Rosas de Oquendo, quien de paso, en el segundo aspecto remarca su composición poética con el empleo de la primera persona singular en tiempo presente 0 , en pretérito perfecto simple ("Digo/metíme/benía/salí") para citar algunos ejemplos. Es la experiencia de un viaje, de su viaje tanto como sujeto escribiente.

Aínsa señala que "(...) la geografía es una metáfora, en tanto representa hechos social y existencialmente relevantes bajo la abstracción de un territorio" (p. 40), por lo que esa metaforización evidente en el empleo de adjetivos calificativos, acompaña al navegante. Asimismo, van desde su salida con el "tiempo dichoso" y con ansias por vivir el viaje en momentos en que los trayectos por barco representaban extensos períodos. La transitividad del desplazamiento también configura metaforizaciones de lo que se ha dejado atrás (los años mozos), del momento presente (mareos, sensaciones físicas y emocionales asociadas a la tempestad) para dar paso, finalmente, a las impresiones y sensaciones que el territorio nuevo pueda brindar (tierra venturosa mirada con los ojos del deseo).

\section{(c) (i) (2)}

La Revista Estudios es editada por la Universidad de Costa Rica y se distribuye bajo una Licencia Creative Commons Atribución-NoComercial-CompartirIgual 3.0 Costa Rica. Para más información envíe un mensaje a 
Dossier: La escritura en los desplazamientos: viajes, expediciones y naufragios

\section{DEL FATIGADO FIN Y REMATE DEL VIAJE DE MATEO ROSAS DE OQUENDO}

22- "AArriva, que nos perdemos!

23- ¡Qué ba a pique la fregata!"

La forma exhortativa reafirma lo señalado en la emergencia, como también puede leerse en las líneas 17, 19 y 22, es el peligro que vislumbra el yo lírico en la indicación colectiva "¡Arriva, que nos perdemos! Las exhortaciones emanadas de la voz indican el accionar ante la emergencia y sujetan a Mateo Rosas de Oquendo, quien se declara un inexperto ante la situación.

Con la línea 28- "El pastor que fue de Betis", el yo lírico conecta referencialmente su conocimiento de las églogas pastoriles, pero su desconocimiento en los asuntos marítimos. Con la autoreferencia al pastor de Betis, él da por sentado un nexo intertextual y cultural que acuerpa su paso por Génova, se declara un hombre de letras y de tierra, no un navegante, reconoce con ello el terror ante la posibilidad del naufragio (versos 22-23). El verso 29 afirma la falta de experiencia en el mar, consolidando su oficio de pastor: su saber en asuntos de tierra y letras. El yo lírico termina por afianzar las circunstancias propias de la emergencia en altamar y de paso, argumenta para los lectores de su romance, las condiciones que el viaje le ha deparado para llegar a América. Rosas de Oquendo, como los cronistas, se enfrenta, desde lo dicho por Alburqueque García, a "(...) una realidad del todo nueva -inabarcable al parecer- y con unos recursos lógicamente limitados a su formación cultural e intelectual" (2011a, p. 34).

No es casual el saber popular en la frase Después de la tormenta viene la calma porque en las líneas 30 y 31, el yo lírico por analogía enuncia: "Mas no ay fiar en el tiempo,/ que el tiempo todo lo acaba" denota con ello el fin de la tormenta; los versos que siguen a la calma evidencian una nueva aventura con la llegada de la

\section{(C) $(0 \bigcirc)$}

La Revista Estudios es editada por la Universidad de Costa Rica y se distribuye bajo una Licencia Creative Commons Atribución-NoComercial-CompartirIgual 3.0 Costa Rica. Para más información envíe un mensaje a revistaestudios.eeg@ucr.ac.cr. 
Dossier: La escritura en los desplazamientos: viajes, expediciones y naufragios embarcación a Cartagena de Indias descubierta en 1533 por Pedro de Heredia, navegante español y primer gobernante de Cartagena:

32- Descubrióse Cartaxena,

33- y señalóse la plaia,

34- que los oxos del deseo

35- por momentos se encontraban.

Después de la tempestad la tierra que se revela ante el yo lírico es la playa de Cartagena de Indias en donde él y otros tripulantes desean descender, pero el capitán no lo permite, advirtiéndoles: 41- "y ninguno a tierra salga". Según se puede deducir del romance, el objetivo del arribo era recoger personas y aparejos, no quedarse allí pues el viaje debía proseguir. El yo lírico manifiesta que lleva consigo dinero suficiente, producto de sus trabajo en la milicia española, para desembarcar en Cartagena (36- Truxe zalario del rrey). El capitán impide la salida a tierra, los versos así lo afirman:

37- $y$, apenas puse las plantas

38- en la benturosa arena,

39- quando el capitán mandava

40- que se recoxa la xente

41 - y ninguno a tierra salga,

Además se muestra el dominio del oficial sobre la tripulación sentenciando que quien baje a tierra, pasará por la horca. El carácter burlesco del yo lírico establece una relación casi de paradoja, con Aínsa coincidimos en hay "referentes de profundo significado simbólico" (2005, p. 44), como lo son el mundo terrenal (la cama) y la posible muerte (la horca). Se exalta además, simbólicamente, la figura del capitán investida de tal poder, que en el contexto del romance ni el ángel de la guarda podría protegerlos como se observa en los versos 44-47:

\section{(c) (i) (2) (2)}

La Revista Estudios es editada por la Universidad de Costa Rica y se distribuye bajo una Licencia Creative Commons Atribución-NoComercial-CompartirIgual 3.0 Costa Rica. Para más información envíe un mensaje a 
44- No quise dormir en horca,

45- que es mexor dormir en cama,

46- que a un rrigor de un capitán

47- no ynporta ánxeles de guarda.

Surge un vacío espacial en la línea del romance pues la situación a la que se enfrenta el yo lírico en Cartagena de desembarcar o no, cede espacio a la llegada a las costas de Nombre de Dios (Panamá). Aínsa acota que "La noción de espacio ha estado tradicionalmente asociada a la idea de hueco y de vacío" (p. 35). Curiosamente, nuestro yo lírico abandona la historia del trayecto de Cartagena de Indias para situarnos en el arribo a Nombre de Dios. La ruta descrita en el romance de Rosas de Oquendo no escapa a los recorridos hechos por los navegantes de la época, como es el caso de Rodrigo de Bastidas quien en 1501 había hecho ese mismo trayecto.

Hay una visión maniquea en la línea 49: -"nombre bueno y tierra mala", el nombre de Dios (bueno) opuesto a esta "tierra mala". Lo atropellado del viaje y el hecho de llegar enfermo, contribuyen a que el yo lírico se forme un mal concepto de las tierras, a lo que podemos sumarle las situaciones ya descritas en el trayecto, además de la figura autoritaria del capitán que nos los dejó desembarcar en Cartagena de Indias y los problemas que enfrentará cuando descienda como a los infiernos a las costas panameñas, isotopía constituida en campo semántico que provee al texto poético de una relación analógica con el Infierno: leemos aisladamente "tierra mala", "calenturas", "pira", "Los Diablos", "fuego":

48- Llegué al Nombre de Dios

49- nonbre bueno y tierra mala,

50 - donde están las calenturas

51- hechas jueses de aduana;

52- pues, al rrigor d'esa pira,

53- es menester que Dios haga

54- a los hombres de pasiencia

55- confirmada con su gracia.

56- Al fin llegué a Panamá

57- sive "Los Diablos la Blanca",

58- tanto que, por no tenella,

59- era mi cama unas tablas.

\section{(๑) $\odot \odot \odot$}

La Revista Estudios es editada por la Universidad de Costa Rica y se distribuye bajo una Licencia Creative Commons Atribución-NoComercial-CompartirIgual 3.0 Costa Rica. Para más información envíe un mensaje a 


\section{Dossier: La escritura en los desplazamientos: viajes, expediciones y naufragios}

Puede plantearse en estas líneas que la noción de espacio físico, como lo refiere Aínsa está determinado por lo que lo rodea y envuelve, es decir "(...) nociones que componen un verdadero «sistema de lugares» del imaginario contemporáneo y un campo semántico de sugerentes significaciones" (p. 41). Es entonces que el hablante lírico crea metáforas del espacio que lo acoge, que a su vez impregnan el lenguaje en esta parte del romance (versos 48-59). El lugar no solo contiene el espacio al que se llega, el espacio también va con el viajero.

Para la experiencia del viajante no es grata la vivencia en estos lares porque aunque acongojado por la premura del traslado, el misterio de la aventura y la convivencia en una embarcación con otros tripulantes, no ha sabido superarse, ni superar que ahora vive novedosas y particulares situaciones. En otras palabras, el imaginario del yo lírico cual equipaje ha sido el dominio del mundo ya conocido y experimentado (España e Italia), que se trastoca ahora por el Nuevo Mundo. Ha cambiado el orden y la racionalidad por el caos.

Consideramos que el viajero en su estadía en las tierras americanas se posiciona en un mundo de vida contrario al que dejó, entonces tendremos un yo lírico vendiendo sus versos para comer, facilitarse medicamentos para curarse, claramente los versos son mercancía en el Nuevo Mundo:

60- Pero la necesidad,

61- como el yngenio adelgaza,

62- balióme la poesía,

63- con que comy dos semanas.

64- Porque hallé un boticario

65- tan rrendido a una mulata,

66- que bolví la nieve fuego

67- con hazelle dos otabas.

68- Entonces agradesí

69- a las musas de Castalia,

70- por este gusto presente,

71- los desdenes de mi dama.

\section{(C) $(000$}

La Revista Estudios es editada por la Universidad de Costa Rica y se distribuye bajo una Licencia Creative Commons Atribución-NoComercial-CompartirIgual 3.0 Costa Rica. Para más información envíe un mensaje a 
ISSN 1659-3316

Barboza Leitón Ivannia

Calvo Oviedo Marlen María

Dossier: La escritura en los desplazamientos: viajes, expediciones y naufragios

Del fragmento anterior reconocemos una nueva constitución del mundo de vida cuando el poeta señala que sus versos desdeñados en tierras españolas por su dama se transforman en este punto preciso en su salvación, las musas de Castalia han sido benéficas para la necesidad que enfrenta en la "tierra mala".

Cabe considerar que el hablante lírico en Respuesta que un amigo escribió a otro (Felisio, tu carta vide) va rumbo a Perú (Lima) como parte del recorrido. Con él hemos realizado el viaje, motivo y pretexto de este artículo, así también hemos analizado el enfrentamiento del yo lírico con América desde su mirada de viajero.

Este romance se enuncia como modelo epistolar que pretende ser la respuesta a la carta de un amigo. No podremos dar fe de la existencia de Felisio o si solo fue el pretexto para crear la respuesta, no obstante, la carta fue una de las tantas formas escritas de la época en que se narró la América hispánica, en este sentido también cumple la función de erigirse como recurso paratextual.

En Respuesta que un amigo escribió a otro (Felisio, tu carta vide) no se abandona el estilo factual por cuanto hay una sucesión de acontecimientos que involucran, como lo refiere Alburquerque García "(...) un sujeto de enunciación de doble experiencia: de viaje y escritura" (2011a, p. 34), convirtiendo ese desplazamiento en la ilación de sucesos enmarcados en un eje espacio-temporal. La movilización que ha representado abordar la nave en España, el recorrido, las experiencias vividas y los puntos de destino consiguen que Mateo Rosas de Oquendo, siguiendo el hilo por el laberinto histórico, nutra con otras posibilidades de escritura y lectura el corpus que dio pie a la naciente América española. Tampoco se despoja de la descriptio que sostiene su transitar literario y geográfico; en esa descripción configura no solo los espacios que conoce, a quienes lo acompañan en la travesía, sino que se describe a sí mismo. Para ello, el yo lírico emplea figuras del discurso, al decir de Alburqueque García, tales como metáfora, símil, prosopopeya, entre otras.

\section{(c) (i)(2)}

La Revista Estudios es editada por la Universidad de Costa Rica y se distribuye bajo una Licencia Creative Commons Atribución-NoComercial-CompartirIgual 3.0 Costa Rica. Para más información envíe un mensaje a revistaestudios.eeg@ucr.ac.cr. 
Dossier: La escritura en los desplazamientos: viajes, expediciones y naufragios

El romance posee el balance que parece en ocasiones perderse cuando de relatos de viaje se trata. Con el carácter que el autor le confiere desde su «yo» posicionado en las circunstancias del desplazamiento de España a América, no hace sino jugar con precisión en los dos bandos realidad y ficción). El primero de ellos compete a la dimensión testimonial ya explicitada líneas arriba, que le otorga un rasgo de verosimilitud en lo que describe y desde una voz individual con cierto carácter emergente (escribir sobre América posee una urgencia de dar testimonio de ese nuevo espacio también). La ficción termina por pintar, desde el tono picaresco, casi burlón del yo lírico, esa realidad transformándola en otra, no es aislado considerar lo que propone Alburqueque García en Crónicas de Indias y relatos de viajes: un mestizaje genérico cuando señala "(...) que esos textos son resultado de unas experiencias vividas por los autores en el transcurso de un viaje, breve o largo, cuyo acto de escritura es posterior a la vivencia y dependiente de objetivos muy distintos (...) (2011a, p. 30).

\section{CONCLUSIONES}

Los relatos de viaje, como hemos podido apreciar son una forma de escritura difícil de conceptualizar, pues en ella se enmarcan distintos elementos venidos del acto de escribir como literatura, de la experiencia personal en tanto se escribe lo vivido y la subjetividad elemental del sujeto que describe, desde un conocimiento previo, de lo que ve. Razón por la que se establece en ellos una lógica que fluctúa entre los relatos de viajes ficticios y los factuales, o una combinación de elementos en un mismo texto realizados por la persona autora.

En el fragmento del romance analizado no se traza una línea de demarcación entre ficción y realidad, sino más bien se solapan al mezclar lo estrictamente documental con el estilo literario del romance. En este sentido el corpus analizado conjuga realidad y ficción, el modelo epistolar (considerado dentro

\section{(c) (i) (2) (2)}

La Revista Estudios es editada por la Universidad de Costa Rica y se distribuye bajo una Licencia Creative Commons Atribución-NoComercial-CompartirIgual 3.0 Costa Rica. Para más información envíe un mensaje a 
ISSN 1659-3316

Barboza Leitón Ivannia

Dossier: La escritura en los desplazamientos: viajes, expediciones y naufragios

de los relatos de viaje) sirve como telón de fondo a la narración de la experiencia de vida de un yo lírico total y completamente asombrado ante los sucesos que le acontecen. El asombro acompaña al hablante lírico a partir del momento en que pone sus pies dentro del barco que lo llevará al Nuevo Mundo y hará con él ese recorrido hasta el destino que lo espera.

En Respuesta que un amigo escribió a otro (Felisio, tu carta vide) hallamos los rasgos característicos del relato de viaje pues se configura un discurso factual con elementos de realismo descriptivo por encima de lo netamente literario como modelo (romance), y la necesidad del lenguaje escrito en la transmisión de la experiencia del viajante, sin que ello implique la pérdida de las características propias del género literario elegido por el propio autor y su transformación en un yo lírico/poeta que además escribe una carta. Todos estos elementos hacen que la voz lírica oscile entre las formas estrictas del romance y su necesidad de escribir y describir la realidad que vive.

Mateo Rosas de Oquendo o el yo lírico, en su desplazamiento no solo conoce y aprehende un mundo nuevo sino que se (re) descubre a sí mismo, nuestro trabajo ha mostrado esos cambios por medio del análisis de los signos que va presentando la voz lírica a lo largo de los distintos versos, esto nos permite, además, asegurar, que el joven que zarpó va transformándose con cada experiencia hasta llegar a ser otro, difícilmente quien zarpa es quien regresa.

La motivación para viajar de este yo lírico no fue la más sublime (huída, alejamiento) pero nos permitió entrar en esta discusión teórica del relato de viaje sustentado en un género literario por demás poético/narrativo y la realidad vivida, como dijimos párrafos más arriba, no nos corresponde valorar la posible ficción en lo narrado. La escritura nos acerca a quienes viajaban al Nuevo Mundo, como en el caso de Mateo Rosas de Oquendo a una visión particular de ocurrencias en la que los viejos signos construyeron el discurso sobre situaciones asombrosas para el vate.

\section{(c) (i)(2)}

La Revista Estudios es editada por la Universidad de Costa Rica y se distribuye bajo una Licencia Creative Commons Atribución-NoComercial-CompartirIgual 3.0 Costa Rica. Para más información envíe un mensaje a revistaestudios.eeg@ucr.ac.cr. 
Dossier: La escritura en los desplazamientos: viajes, expediciones y naufragios

Cuando leemos y analizamos Respuesta que un amigo escribió a otro (Felisio, tu carta vide), el pasado y el presente se funden, a través del acto de escribir, en la magnificencia del mundo contado, no únicamente como espacio sino también como amalgama de símbolos, sensaciones y experiencias, unidas en y desde un género literario y la vivencia propia del viajante/poeta/narrador.

\section{REFERENCIAS BIBLIÓGRAFICAS}

Aínsa, F. (2005). Espacio literario y fronteras de la identidad. San José: Editorial de la Universidad de Costa Rica.

Alburqueque García, L. (2011a). Crónicas de Indias y relatos de viaje: un mestizaje genérico. En P. Latasa (Ed.), Discursos coloniales: texto y poder en la América (pp. 29-42). España: Iberoamericana Vervuert.

Alburqueque García, L. (enero, junio 2011b). El 'relato de viajes': hitos y formas en la evolución del género. Revista de Literatura, LXXII(145), 16-34.

Carilla, E. (1996). Poesía novoshispana del siglo XVI. Mateo Rosas de Oquendo (¿1559? ¿1612?). En B. Garza Cuaron y G. Baudot (Coords.), Historia de la Literatura Mexicana desde sus orígenes hasta nuestros días 1. Las literaturas amerindias de México y la literatura en español del siglo XVI (pp. 416-449). Ciudad de México: Siglo XXI Editores.

Carriazo, J. (enero,1999). "El término fragata en el paso del español clásico al moderno. Revista de lexicografía, 5, 33-44. Recuperado de https://dialnet.unirioja.es/servlet/articulo?codigo $=185380$

\section{c) (i) (2)}

La Revista Estudios es editada por la Universidad de Costa Rica y se distribuye bajo una Licencia Creative Commons Atribución-NoComercial-Compartirlgual 3.0 Costa Rica. Para más información envíe un mensaje a revistaestudios.eeg@ucr.ac.cr. 
Dossier: La escritura en los desplazamientos: viajes, expediciones y naufragios

Cirlot, J. (1997). Diccionario de símbolos. 3a ed. Madrid: Ediciones Siruela.

Eisenberg, D. (1991). El romance visto por Cervantes. Estudios Cervantinos. Alicante: Biblioteca Virtual Miguel de Cervantes. Recuperado de: http://www.cervantesvirtual.com/nd/ark:/59851/bmc0g3x5

Gómez, J. (1991). Sobre la teoría de la bucólica en el Siglo de Oro: hacia las églogas de Garcilaso. Dicenda 10, 111-26.

Lasarte, P. (1988). Apuntes bio-bibligráficos y tres inéditos de Mateo Rosas de Oquendo. Revista de Crítica Literaria Latinoamericana 14 (28) ,85-99. DOI: $10.2307 / 4530392$.

Lasarte, P. (marzo 1990). Mateo Rosas de Oquendo y la escritura autobiográfica. MLN, 2, (105), 373-384. DOI: 10.2307/2905300.

Magariños del Morentin, J. Á. (1996). Los fundamentos lógicos de la semiótica y su práctica. Argentina: EDICIAL.

Menéndez Pidal, R. (1953). Romancero hispánico. Teoría e historia. Tomo II. Madrid: Espasa-Calpe.

Paz y Meliá, A. (1906). Cartapacio de diferentes versos á diversos asuntos, compuestos ó recogidos por Mateo Rosas de Oquendo. Bulletin hispanique, 8(2), 154-162. DOI: https://doi.org/10.3406/hispa.1906.1484.

\section{(c) (i) (2)}

La Revista Estudios es editada por la Universidad de Costa Rica y se distribuye bajo una Licencia Creative Commons Atribución-NoComercial-CompartirIgual 3.0 Costa Rica. Para más información envíe un mensaje a 
ISSN 1659-3316

Barboza Leitón Ivannia

Dossier: La escritura en los desplazamientos: viajes, expediciones y naufragios

Peña, M. (1986). "El "Cartapacio poético" de Rosas de Oquendo: una muestra de poesía satírica colonial". Actas del IX Congreso de la Asociación Internacional de Hispanistas. 2, 667-678. Recuperado de https://dialnet.unirioja.es/servlet/articulo?codigo $=594186$.

Pérez de Tudela Oviedo, R. (2008). Reseña de 'Aquí ninfas del sur, venid ligeras'. Voces poéticas virreinales de Raquel Chan Rodríguez. En Anales de Literatura Hispanoamericana, (pp. 348-350), 37, Madrid: Iberoamericana Verbuert

Reyes, A. (1957). Capítulos de literatura española. Primera y segunda series. 1a edición. México: Fondo de Cultura Económica.

Rodilla León, M. J. (I semestre, 1998). Espacio simbólico y sociedad en un relato de la Colonia: La Endiablada (c1624) de Mogrovejo de la Cerda. Kipus: Revista Andina De Letras, 8, 77-83. Recuperado de http://hdl.handle.net/10644/1783

ANEXO N. 1

Respuesta que un amigo escribió a otro (Felisio, tu carta vide (¿1598?), fragmento

1- Digo que salí d’España

Mateo Rosas de Oquendo

2- en berdor de mis años

3- y el abril de mi esperança,

4- quando Fenis, mi enemiga,

5- tan hermosa como yngrata,

6- quiso pagar a mi fe

La Revista Estudios es editada por la Universidad de Costa Rica y se distribuye bajo una Licencia Creative Commons Atribución-NoComercial-CompartirIgual 3.0 Costa Rica. Para más información envíe un mensaje a revistaestudios.eeg@ucr.ac.cr. 
Dossier: La escritura en los desplazamientos: viajes, expediciones y naufragios

7- la deuda en que se hallaba.

8- En este tiempo dichoso

9- salió Belisa a la causa, 10- rrompiendo mares de fe, 11- que no hay para el ielo ama-

12- Desterróme y desterréme;

13- metíme en una fregata:

14- alsaron belas al viento, 15- xunto con la de mis ansias.

16- Bramó el mar, cresió los

17- davan mil boses: « Amaina!

[bientos;

18- ¡Rrecoxe la sebadera!

19- ¡Echa el timón a la banda!»

20- Unos llamavan a Dios,

21- otros a su madre llaman:

22- "¡Arriva, que nos perdemos!

23- Qué ba a pique la fregata!"

24- Yo benía almadiado

25- como pescado en el agua,

26- tan pribado de sentido

27- como lo salí d'España.

28- El pastor que fue de Betis,

29- consideraba quál estaba.

30- Mas no ay fiar en el tiempo,

31- que el tiempo todo lo acaba.

32- Descubrióse Cartaxena,

33- y señalóse la plaia,

34- que los oxos del deseo

35- por momentos se encontraban.

36- Truxe zalario del rrey

37- $y$, apenas puse las plantas

38- en la benturosa arena,

39- quando el capitán mandava

40- que se recoxa la xente

41- y ninguno a tierra salga,

42- y el que esta ley no cumpliere,

43- le colgará si le halla.

44- No quise dormir en horca,

45- que es mexor dormir en cama,

La Revista Estudios es editada por la Universidad de Costa Rica y se distribuye bajo una Licencia Creative Commons Atribución-NoComercial-CompartirIgual 3.0 Costa Rica. Para más información envíe un mensaje a 
Dossier: La escritura en los desplazamientos: viajes, expediciones y naufragios

46- que a un rrigor de un capitán

47- no ynporta ánxeles de guarda.

48- Llegué al Nombre de Dios

49- nonbre bueno y tierra mala,

50- donde están las calenturas

51- hechas jueses de aduana;

52- pues, al rrigor d'esa pira,

53- es menester que Dios haga

54- a los hombres de pasiencia

55- confirmada con su gracia.

56- Al fin llegué a Panamá

57- sive "Los Diablos la Blanca",

58- tanto que, por no tenella,

59- era mi cama unas tablas.

60- Pero la necesidad,

61- como el yngenio adelgaza,

62- balióme la poesía,

63- con que comy dos semanas.

64- Porque hallé un boticario

65- tan rrendido a una mulata,

66- que bolví la nieve fuego

67- con hazelle dos otabas.

68- Entonces agradesí

69- a las musas de Castalia,

70- por este gusto presente,

71- los desdenes de mi dama.

72- No escapé de Panamá

73- sin tener chapetonadas

74- quatro meses por lo menos,

75- y todos fueron sin blanca.

76- Dio la fortuna en seguirme,

77- ella save por qué causa,

78- xusto castigo del sielo,

79- pago de mis arrogancias.

80- Vi la grosedá de Lima...

La Revista Estudios es editada por la Universidad de Costa Rica y se distribuye bajo una Licencia Creative Commons Atribución-NoComercial-CompartirIgual 3.0 Costa Rica. Para más información envíe un mensaje a 